\title{
Modelling and Fuzzy-Threshold Control of SI Engine for Emission Reduction during Cold Start Phase
}

\section{O. Khalilikhah and M. Shalchian*}

Electrical Engineering Department, Amirkabir University of Technology, 15875-4413 Hafez Ave, Tehran, Iran

*Email: shalchian@aut.ac.ir

\begin{abstract}
We present a controllable model of an internal combustion engine that captures the overlapping of the cylinder valves as a controllable parameter and its effect on engine efficiency and EGR rates. The model parameters have been calibrated for the EF7 engine and validated with experimental data. This model successfully estimates the performance and $\mathrm{HC}$ and NOx emissions concentration of the engine under cold start operating condition. A model-based fuzzy-threshold control strategy has been proposed in cold start operating condition. This strategy uses the overlapping angle of the cylinder inlet and outlet valves as an extra degree of freedom in comparison to the regular PID strategy in order to accelerate the warm-up duration the catalyst converter while reduces the exhaust harmful emissions during the warm-up phase. The proposed controller model has been verified in MATLAB Simulink environment and simulation results indicates $8.6 \%$ reduction of the start-up time of the catalyst converter and reduction of $3.5 \%, 8.5 \%$ and $7 \%$ of $\mathrm{HC}, \mathrm{NO}$ and fuel consumption respectively during the catalyst warm-up phase.
\end{abstract}

Keywords: Cold start; engine control strategy; VVT system; fuzzy-threshold controller; emission reduction.

\section{INTRODUCTION}

Today, air pollution from vehicle emissions is increasing rapidly, particularly in large cities. One of the most polluting situations during vehicle operation is the cold start duration. For modern vehicles equipped with a spark-ignition engine come with fuel injection and electronic mixture control, in combination with a three-way catalyst, fuel consumption and cold start extra-emissions detected during the cold transient time are deeply higher compared with those obtained during thermally stable operation [1]. Cold start duration begins from the cold vehicle startup (A car that had been switched-off for 12 to 36 hours in an environment with 20 to 30 degrees Celsius [2]) until the catalyst warm-up to its working temperature. The warm-up and the cold transient are crucial periods of gasoline engines operation. These periods have the highest contribution to the vehicle's pollution for several reasons. Due to increased friction of the engine in cold transient time, stable engine operation demands rich air to fuel ratio outside the optimum range of catalyst efficiency [3], besides, liquid fuel impingement on cold surfaces of the engine, resulting in an undesirable fuel-air mixture [4], finally low conversion efficiency of the catalyst before warming up yields to high emission level in these phases [2].

To develop a control strategy aimed at reducing harmful emissions in the cold start phase, we need a suitable and controllable engine model in this phase. Several mean value 
and controllable models have been proposed to catch cold start operating condition by Farzad Keenezhad, Chris Manzi and their colleagues in [5-7]. These models have been presented for designing controllers to improve emissions, fuel consumption and performance of cold start condition. In [8,9] an approximate model, called the high-level model is presented by Carl Hedrick and his colleagues. In [10,11], the controllable models of an SI engine were presented in cold start phase, this model was further used to reduce emission and fuel consumption in the cold start phase. These models have an experimental basis, but they have not including the effect of intake and exhaust valve overlapping (VO) on air pollution and volumetric efficiency. Moreover, the models of the exhaust path, particularly, the model of catalyst temperature, are very complicated and requires calibration of many parameters [6].

In [12], a physical model of the SI engine was presented then, a fuzzy control algorithm was developed, and results demonstrated the effectiveness of this control method. We propose a simple model for engine operating during cold start. The strength of the proposed model in comparison to the existing models is its ability to model the effect of VO on the volumetric efficiency, as well as the engine speed, and on the EGR rate. Using VVT system and the VO mechanism, especially in the cold start phase, the volumetric efficiency of the engine is increased, and thus the engine speed and exhaust gases flow are increased, and the catalytic converter is heated up faster and reduce cumulative exhaust emissions. Besides, the EGR (exhaust gas recirculation) can be applied with proper control of this system and therefore $\mathrm{NO}_{\mathrm{x}}$ and $\mathrm{HC}$ harmful emissions are reduced [13, 14]. This control strategy is applied in the form of a controller called the fuzzy controller to the model. In this controller, the spark ignition angle is controlled based on fuzzy inference, because these types of controllers are appropriate for controlling nonlinear systems [12]. Besides the VO angle is controlled by a specific threshold of engine speed.

\section{ENGINE MODEL IN COLD START}

The top-level structure of the model is shown in Figure 1. This model consists of three main sections. The first section is the mean value model of engine, the second section is the exhaust system temperature model and the third section is the exhaust emission model that calculates harmful emissions such as $\mathrm{NO}_{\mathrm{x}}$ and $\mathrm{HC}$.

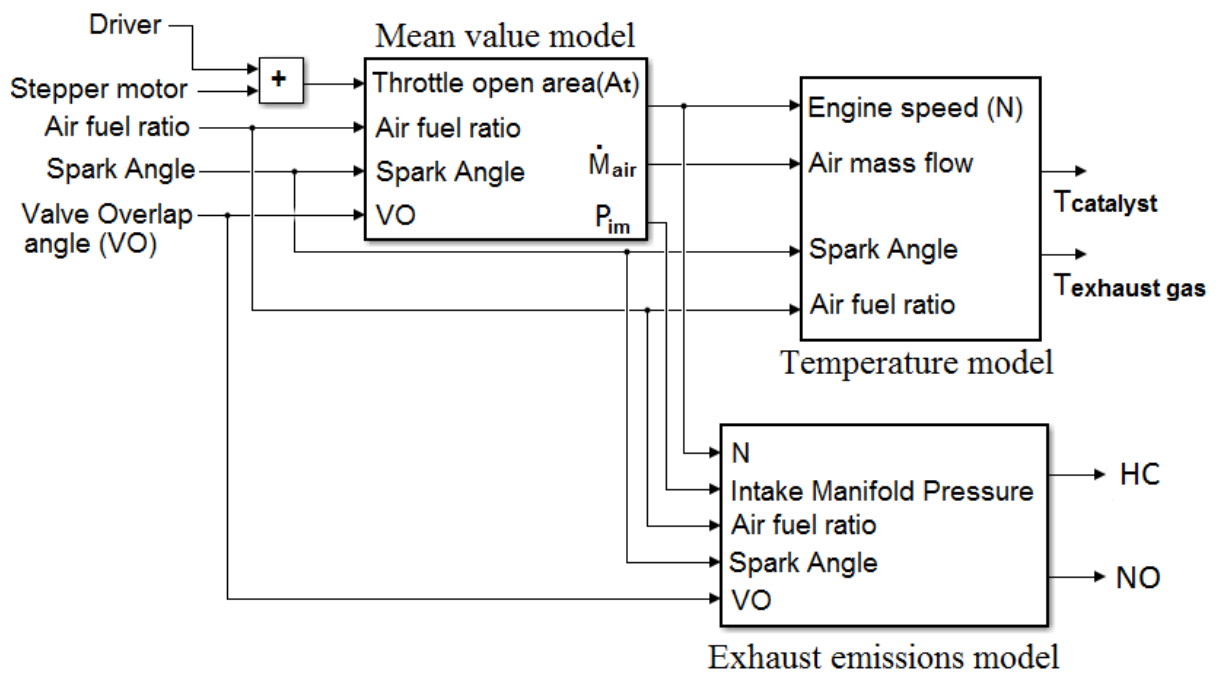

Figure 1. Top-level structure of the model. 
Carbon monoxide $(\mathrm{CO})$ has the same behaviour as unburned hydrocarbons pollutant. So, to reduce the modelling complexity it is excluded $[15,16]$. Table 1 and Table 2 list equations related to the mean value model of the engine.

Table 1. Mean value model equations for the air mass flow, manifold pressure and engine speed calculations.

\begin{tabular}{|c|c|c|c|}
\hline Equations & & & Parameters \\
\hline Air mass flow into inlet manifold [6] & & $P_{a m b}$ & ambient pressure \\
\hline$\dot{M}=C_{D} A_{t} P_{a m b}\left(\frac{P_{i m}}{\frac{1}{\gamma}} \times\left[2 \gamma\left(1-\left(\frac{P_{i m}}{\frac{\gamma-1}{\gamma}}\right]^{0.5}\right.\right.\right.$ & (1) & $T_{a m b}$ & $\begin{array}{l}\text { ambient } \\
\text { temperature }\end{array}$ \\
\hline$\sqrt{R T_{a m b}} P_{a m b}\left[\gamma-1\left(\begin{array}{ll}1 & P_{a m b}\end{array}\right)\right]$ & & $P_{i m}$ & $\begin{array}{l}\text { intake manifold } \\
\text { pressure }\end{array}$ \\
\hline $\begin{array}{l}C_{D}=a_{1} A_{t}^{2}+a_{2} A_{t}+a_{3} \\
a_{1}, a_{2}, a_{3}: \text { calibration coefficients for nonlinear relation of } \\
\text { air mass flow to throttle open area }\end{array}$ & (2) & $\gamma$ & $\begin{array}{l}\text { specific heat } \\
\text { capacity ratio at } \\
\text { constant pressure } \\
\text { to constant } \\
\text { volume }\end{array}$ \\
\hline & & $A_{t}$ & $\begin{array}{l}\text { throttle open area } \\
\text { (main and bypass) }\end{array}$ \\
\hline & & $R$ & constant gas \\
\hline & & $C_{D}$ & $\begin{array}{l}\text { throttle discharge } \\
\text { coefficient }\end{array}$ \\
\hline Flow of air /fuel mixture entering the cylinder & (3) & $\beta$ & $\begin{array}{l}\text { stoichiometric } \\
\text { air/fuel ratio }\end{array}$ \\
\hline$M_{c y l}=\left(\frac{\rho}{\beta}\right)\left(\right.$ slop $\left.\times P_{i m}-o f s\right)$ & & $V O$ & $\begin{array}{l}\text { valve overlap } \\
\text { angle }\end{array}$ \\
\hline & & $N$ & engine speed \\
\hline $\begin{array}{l}\text { slop }=\left(\frac{0.25}{9}(V O-6)-2.44\right)\left(\frac{N-992}{512}\right)+\left(\frac{0.27}{9}\right)(V O-6)+4.53 \\
o f s=\left(\begin{array}{c}o f_{2}+o(1504-N) o f_{1}- \\
o_{2}(N-992) o f_{2}-o f_{1}\end{array}\right) \times\left(\frac{N-992}{512}\right)+o f_{1} \\
o f_{1}=\frac{0.41}{9}(V O-6)+3.34 \quad o f_{2}=\frac{-1.44}{9}(V O-6)+5.78\end{array}$ & (5) & $\begin{array}{l}\text { slop a } \\
\text { meas } \\
\text { vehic } \\
\text { condi } \\
\text { engin } \\
\text { overl } \\
\text { paran } \\
\text { ECU } \\
\text { Unit) }\end{array}$ & $\begin{array}{l}\text { ld ofs based on } \\
\text { rement data from } \\
\text { under different } \\
\text { ions as a function of } \\
\text { speed and valve } \\
\text { p angle. These } \\
\text { eters are stored in } \\
\text { Electronic Control } \\
\text { s look up table. }\end{array}$ \\
\hline & & $o f_{1,2}$ & $V O$ effects on $o f s$ \\
\hline Inlet manifold pressure $[6,10]$ & (6) & $V_{i m}$ & $\begin{array}{l}\text { inlet manifold } \\
\text { volume }\end{array}$ \\
\hline$\frac{\partial P_{\text {im }}}{\partial t}=\frac{\gamma-1}{V_{i m}} \times\left(M_{\text {air }}\left(C_{p}+\frac{C_{P \text { fuel }}}{\beta}\right)-M_{c y l} C_{p}\right)$ & & $C_{P}$ & $\begin{array}{l}\text { specific heat } \\
\text { capacity at } \\
\text { constant pressure }\end{array}$ \\
\hline & & $C_{p \text { fuel }}$ & $\begin{array}{l}\text { specific heat } \\
\text { capacity of fuel }\end{array}$ \\
\hline Engine speed [6] & & $\tau_{\text {crank }}$ & produced torque \\
\hline$\frac{\partial N}{\partial}=\frac{\tau_{\text {crank }}-\tau_{\text {fric }}-\tau_{\text {brake }}}{I}$ & (7) & $\tau_{\text {fric }}$ & frictional torque \\
\hline$\partial t$ & & $\tau_{\text {brake }}$ & brake torque \\
\hline & & $J$ & $\begin{array}{l}\text { moment of inertia } \\
\text { of crankshaft }\end{array}$ \\
\hline
\end{tabular}


Table 2. Mean value model equations for engine torque and efficiencies of the engine

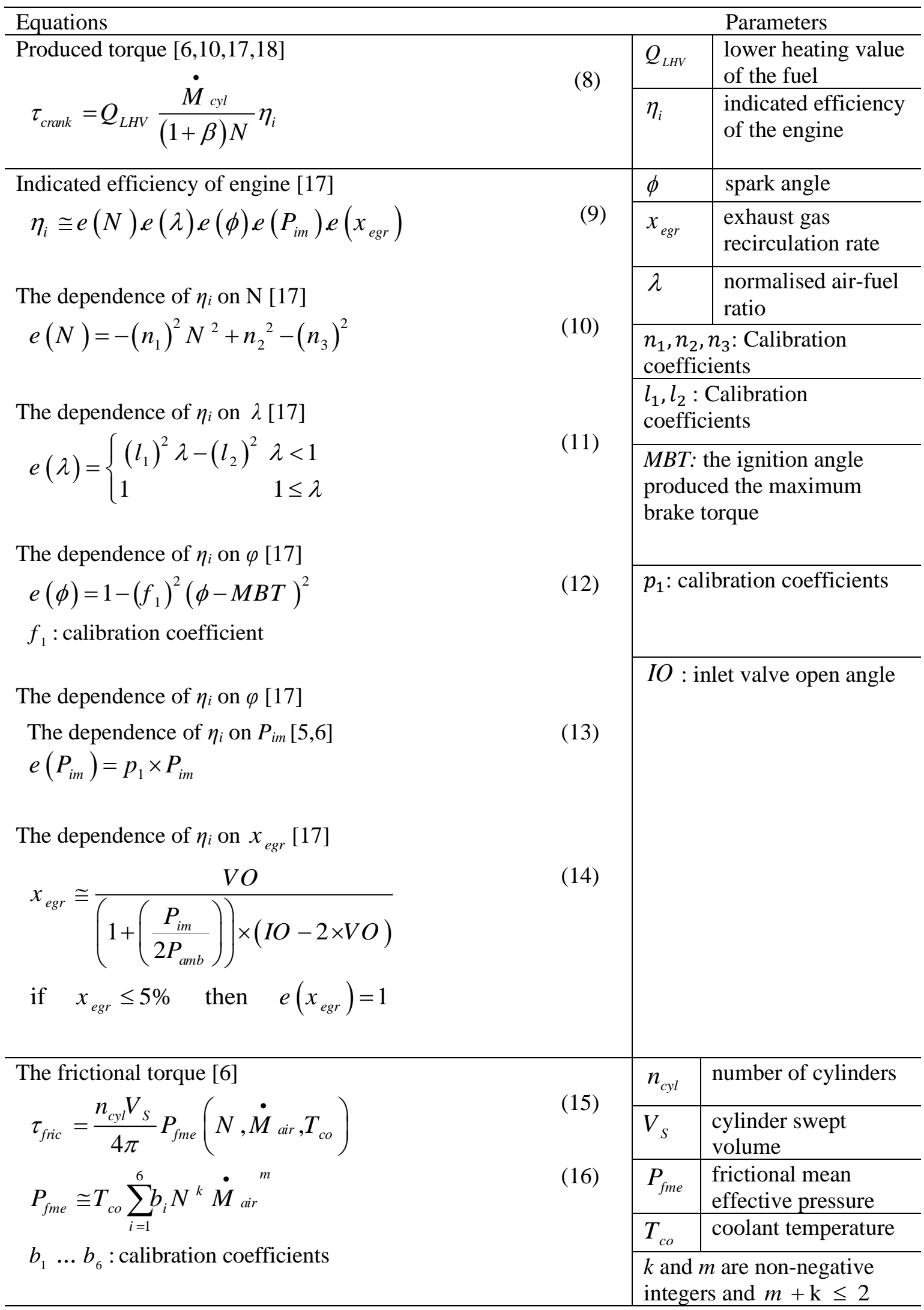




\section{Exhaust System Temperature Model}

The second part of the model estimates the mean temperature of the exhaust gas before the catalyst converter and the mean temperature of the catalyst converter itself by using relevant lookup tables stored in ECU. Figure 2 shows a flowchart for temperature estimation. At the beginning of the cold start phase due to the large difference between the gas temperature and the exhaust system (Outlet manifold, pipes, outlet connections and catalyst converter) temperature, water vapour in the combustion gas is condensed in the exhaust system and dew is produced. The dew prevents heat transfer from the combustion gas to the exhaust system. Therefore, the temperature of the exhaust system does not change much before dew evaporation. The temperature that dew is completely evaporated is a threshold called the dew point. It depends on the cumulative amount of exhaust gas flow that can lead to the evaporation of dew and calculated by the ECU as a function of ambient temperature and the initial temperature of the engine coolant $\left(T_{c o}\right)$. In this algorithm, $T_{S}$ is the steady-state temperature of combustion gas, which is a function $(f)$ of air mass flow $(M A F)$, engine speed, spark angle and air-fuel ratio in the after dew point condition and $T_{S}$ in the under dew point condition is a function of $T_{c o}$. Since the value of this variable in the cold start phase is lower than its nominal value, then the value of this variable should be reduced as much as $T_{\text {sub }}$ (Which is a function of the $T_{c o}$ and cumulative value of the air mass flow in the after dew point condition and $T_{s u b}$ in the under dew point condition is a function of $T_{c o}$ ). $C_{h}$ is the heat transfer coefficient between the combustion gas and the exhaust system, which is a function of the air mass flow (all of these functions has been stored in ECU in the form of lookup tables). The one-dimensional differential equations describing the $T_{S}-T_{s u b}$ and mean temperature of the catalyst converter are based on [6], which equations are complex and require calibration of many parameters. Next, the mean temperature of the exhaust gas $\left(T_{g}\right)$ is converted to the mean temperature of the catalyst converter by a calibration table.

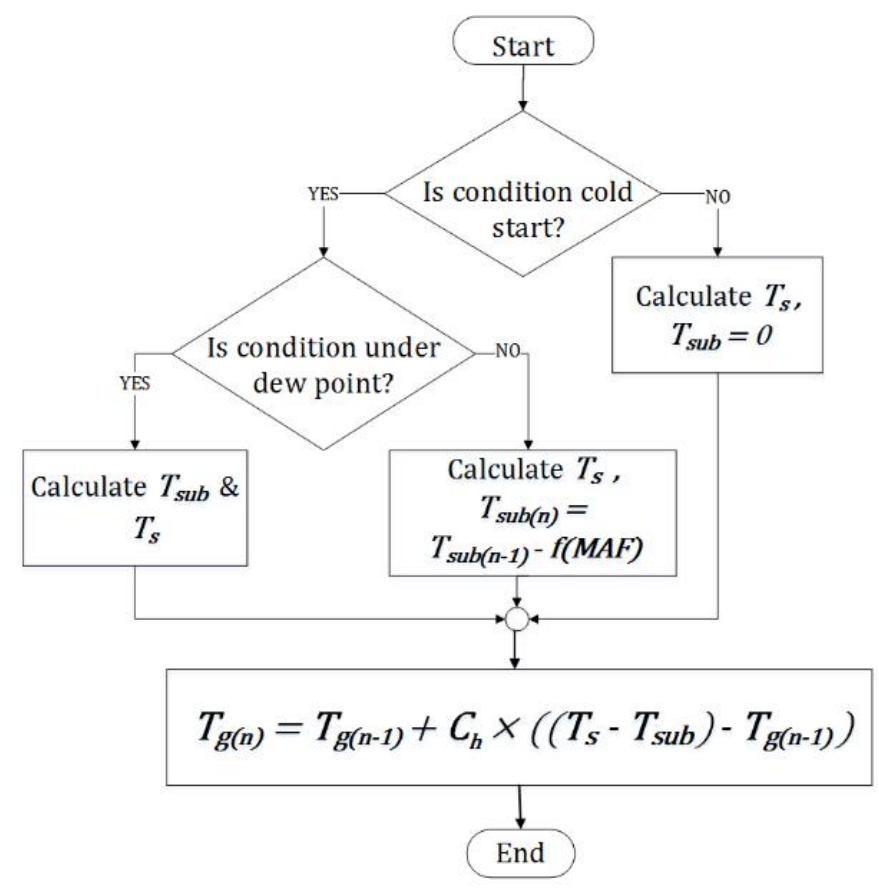

Figure 2. Flowchart for catalyst temperature estimation. 


\section{Exhaust Emissions Model}

This part is based on a feed-forward dual-layer neural network that calculates the concentration of harmful exhaust emissions such as unburned hydrocarbons and nitrogen monoxide in $\mathrm{ppm}$ with accurate precision. Activation function for neurons of the hidden layer is sigmoid and for neurons of the output is linear. The training algorithm, the number of neurons in the neural network and the division of data (training $=60 \%$, validation $=30 \%$ and test $=10 \%$ ) are selected to minimise the error of the test data, without overtraining. For this purpose, numerous data sampling from exhaust emissions and engine parameters have been executed. The obtained data are used to verify the performance of the neural network and to verify the lack of overtraining. Table 3 shows the neural network specifications and normalized root mean square error (NRMSE) [6] and the linear regression (R) obtained for the test data. Model inputs for calculation of unburned hydrocarbons and nitrogen monoxide emissions are based on (17), (18) respectively [6]:

$$
\begin{aligned}
& H C=f\left(P_{i m}, \lambda, V O, N, \phi\right) \\
& N O=f\left(P_{i m}, \lambda, V O, N, \phi\right)
\end{aligned}
$$

Table 3. Neural network specifications.

\begin{tabular}{lcc}
\hline & $\mathrm{HC}$ & $\mathrm{NO}$ \\
\hline Training algorithm & Trainbr & Trainscg \\
\# of hidden layer neurons & 9 & 40 \\
NRMSE & 0.014 & 0.022 \\
$\mathrm{R}$ & 0.9989 & 0.9984 \\
\hline
\end{tabular}

\section{Experimental Setup}

Measurements are performed on SAMAND vehicle with the EF7 engine, with the specification listed in Table 4. To prepare the experimental setup, As shown in Figure 3(a), two temperature sensors have been installed in the exhaust system, first, one at the end of the outlet manifold and the second one is located inside the catalyst converter, to measure the mean temperature of the combustion gas and the catalyst converter. Besides, a wideband oxygen sensor (UEGO) was installed and at the entrance of the catalyst converter and preheated to measure air to fuel ratio during the cold start with high accuracy. To test at the cold start, the vehicle engine had been shut off for about 20 hours. Data sampling is performed with no load on the engine (idle operating state). The ambient temperature, engine coolant and engine oil have been measured at a starting point $\left(25^{\circ} \mathrm{C}\right)$.

The arrangement of the test setup used for data sampling is shown in Figure 4(a) and 4(b). To measure the exhaust emission concentration, AVL DITEST GAS 1000 gas analyser has been used and shown in Figure 3(b). To completely eliminate the effect of the catalyst on the measured emission concentration, the exhaust gases have been sampled before the catalyst converter. 
Table 4. EF7 Engine parameters.

\begin{tabular}{lc}
\hline Parameter & Value \\
\hline Cylinder & 4 \\
Engine displacement & $1700 \mathrm{~cm}^{3}$ \\
Max power & $84.26 \mathrm{~kW} \mathrm{@6000} \mathrm{RPM}$ \\
Top speed & $190 \mathrm{~km} / \mathrm{h}$ \\
System cooling & Water-cooling \\
Compression ratio & $0.2: 1$ \\
Valve & 16 \\
VO duration & $0-60$ CAD \\
Fuel system & Electronic port fuel injection \\
\hline
\end{tabular}

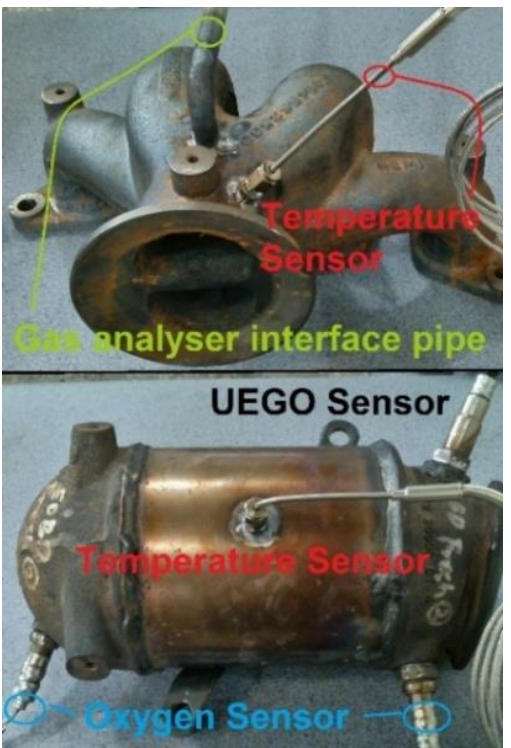

(a)

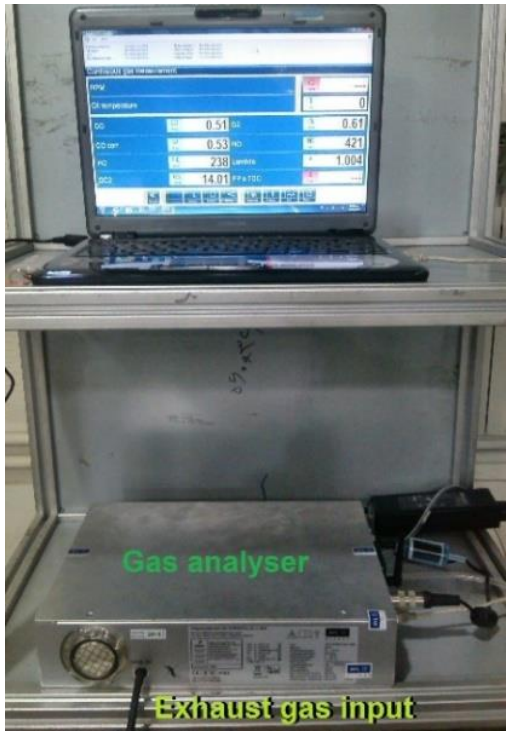

(b)

Figure 3. (a) Temperature sensor 1 and gas analyser interface pipe installed at exhaust manifold and temperature sensor 2 and UEGO sensor installed at catalyst converter.

(b) AVL DITEST gas 1000

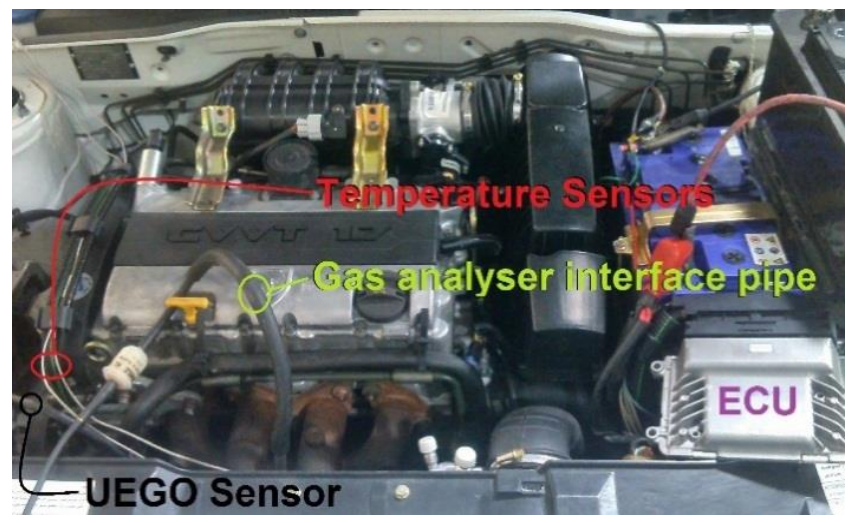

(a)

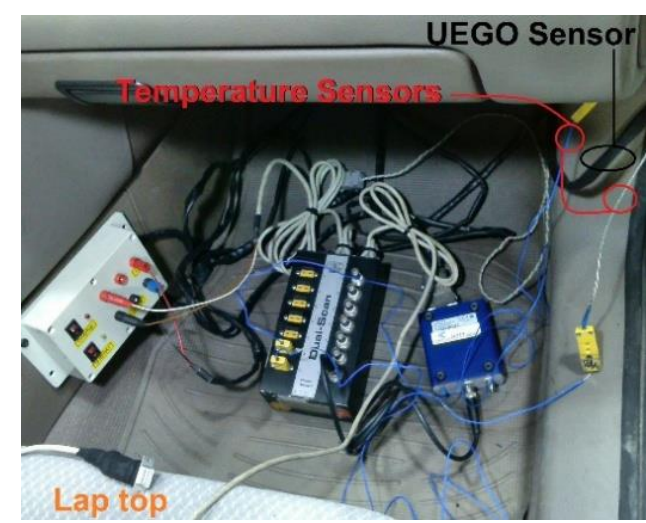

(b)

Figure 4. (a) Exhaust gas interface pipe and interface wire of sensors on vehicle.

(b) Equipment of data sampling and communication with computers. 


\section{Calibration of Model Parameters}

The parameters of mean value SI engine model have been fitted to model using the measured data and system functional characteristics and their fitting based on Eq. (19):

$$
x=\arg \min _{x} \sum_{i=1}^{n}\left[d_{i}(x)-D_{i}\right]^{2}
$$

where $x$ is a calibration coefficient, which is obtained to minimises the sum of squared deviation of the model $(d)$ from the measured data $(D)$ over several samples $(n)$ [6]. Measured parameters used to determine the calibration coefficients are listed in Table 5. The parameters of the exhaust system temperature model are extracted from the calibration curves stored in the ECU.

Table 5. Measured parameter for calibration of the model.

\begin{tabular}{lcc}
\hline Modelled parameter & Measured parameter & Calibration factor \\
\hline$C_{D}$ & $A_{t}$ & $a_{1}, a_{2}, a_{3}$ \\
slop, ofs & slop, ofs & $o_{1}, o_{2}$ \\
$\tau_{\text {fric }}$ & $\tau_{\text {fric }}$ & $b_{1} \ldots b_{6}$ \\
$\eta_{i}$ & $\dot{M}_{\text {cyl }}, N, \lambda, \tau_{\text {fric }}, \phi, P_{\text {im }}, V O$ & $n_{1}, n_{2}, n_{3}, l_{1}, l_{2}, f_{1}, p_{1}$ \\
\hline
\end{tabular}

\section{Model Validation}

The output signals from three sections of the model (Section 1: $\left[\dot{M}_{\text {air }}, \dot{M}_{c y l}, P_{i m}, N\right]$, Section 2: $\left[T_{\text {catalyst }}, T_{\text {exhaust }}\right]$, Section 3:[NO $\left.\left.{ }_{x \text { emission }}, H C_{\text {emission }}\right]\right)$ have been compared with the measured data as shown in Figure 5 to 7 respectively. These results confirm that the proposed model follows experimental results with high accuracy. Table 6 summarises the mean absolute percentage error (MAPE) of the model outputs relative to the measured values. Average MAPE is $1.22 \%$ during 80 seconds from engine start at cold phase, and the maximum MAPE is $3.02 \%$, which is related to the simulation of $\mathrm{NO}_{\mathrm{x}}$ emission.

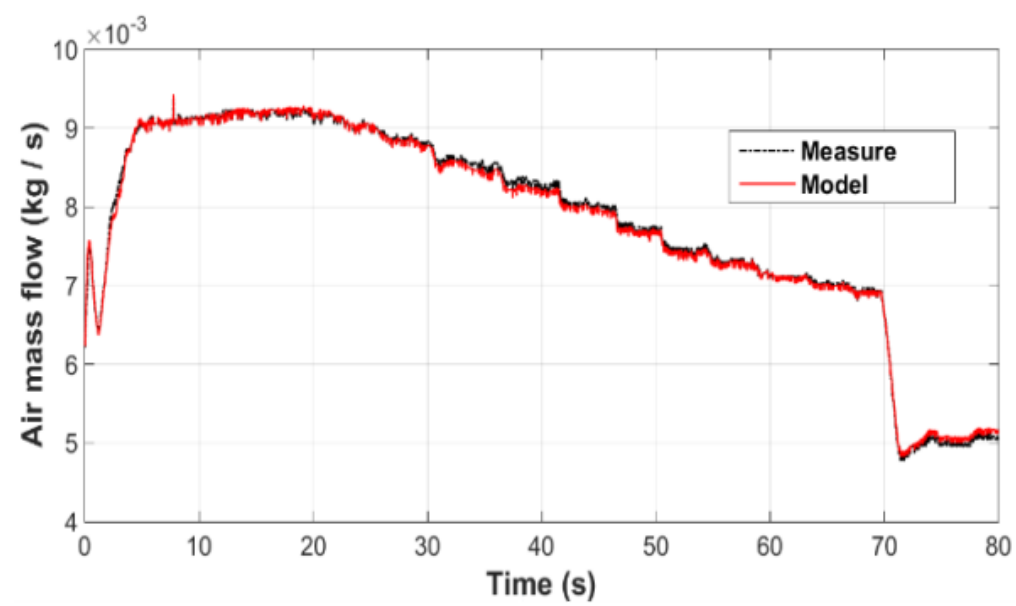

(a) 


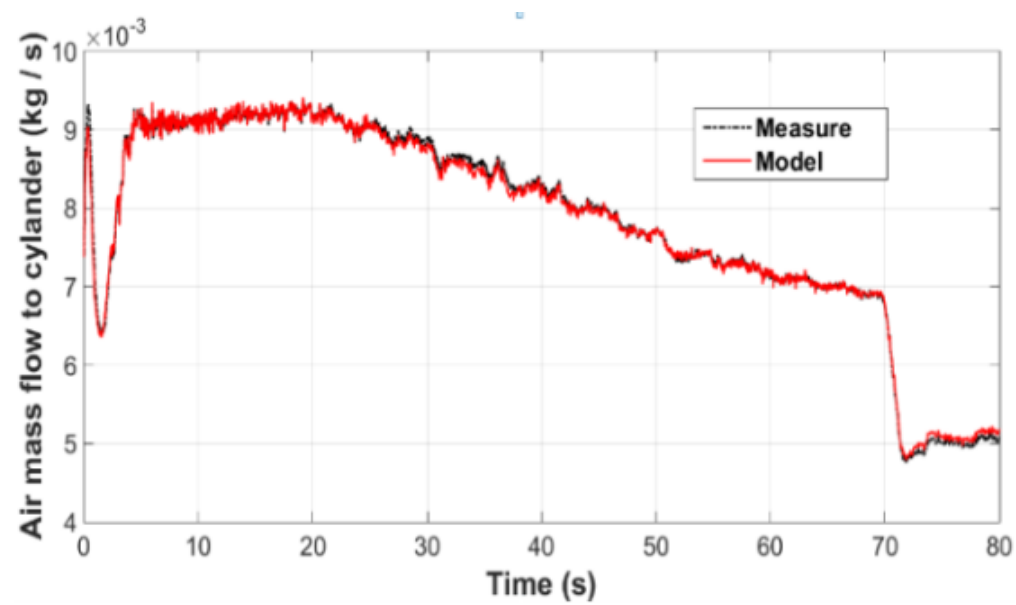

(b)

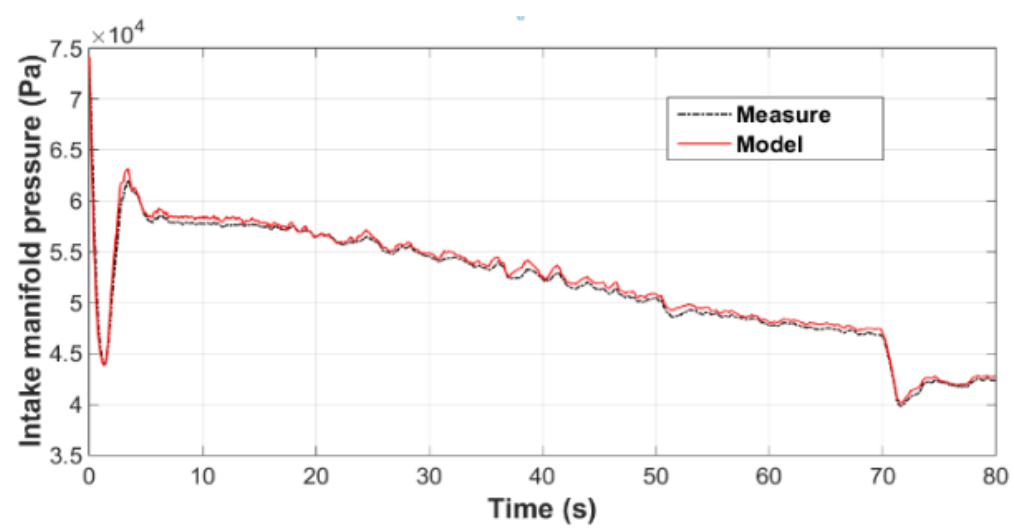

(c)

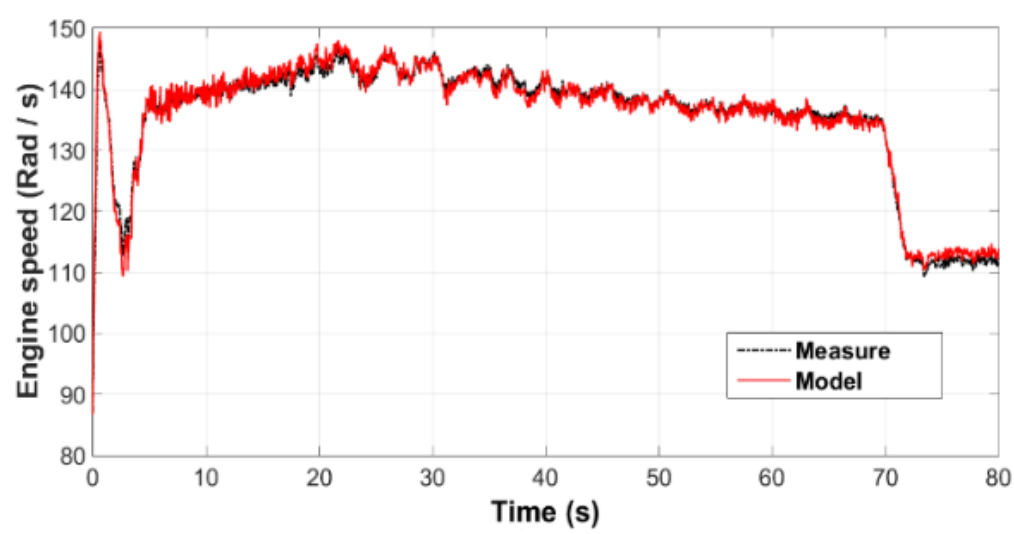

(d)

Figure 5. (a) Manifold air mass flow, (b) air mass flow into the cylinder, (c) intake manifold pressure and (d) engine speed (red line: model, black dotted line: measurement).

Figure 6 (b) shows that the proposed model, accurately predicts the mean temperature of the catalyst converter before catalyst light on $\left(\mathrm{T}_{\text {catalyst }}<700^{\circ} \mathrm{K}\right)$. But above this threshold, due to the exothermic reactions inside catalyst, its temperature increases, beyond model prediction, but this is not an issue since we concern about the accuracy of the model only during cold start phase. 


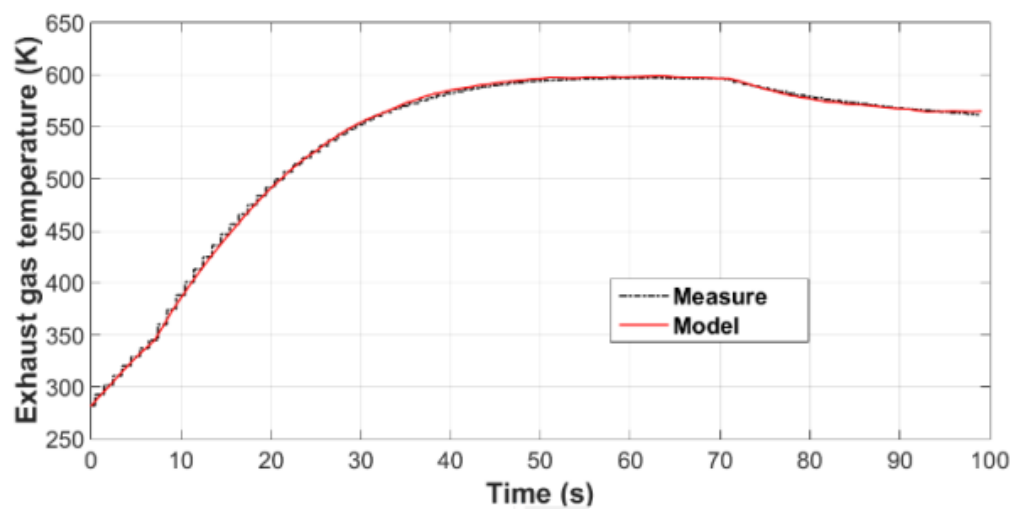

(a)

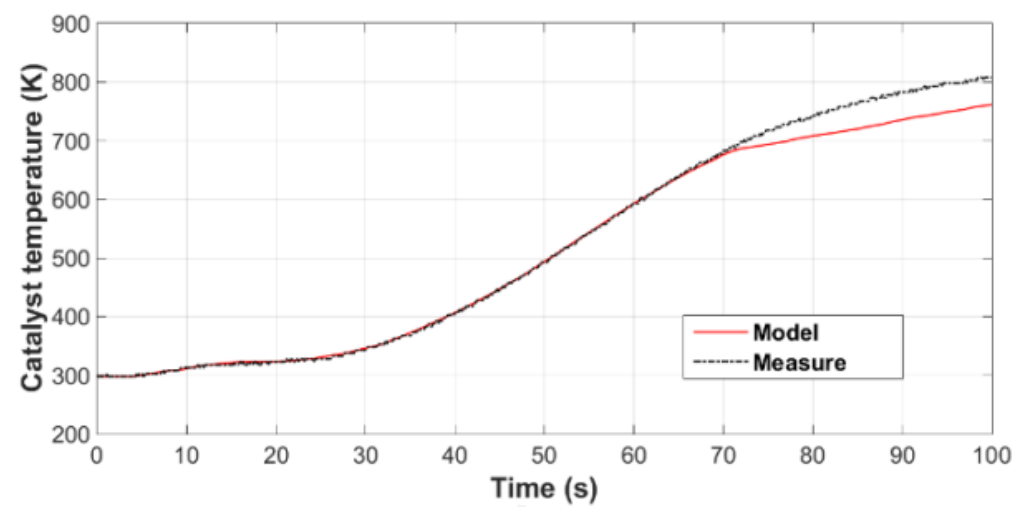

(b)

Figure 6. (a) Exhaust gas temperature and (b) catalyst temperature. (red line: model, black dotted line: measurement)

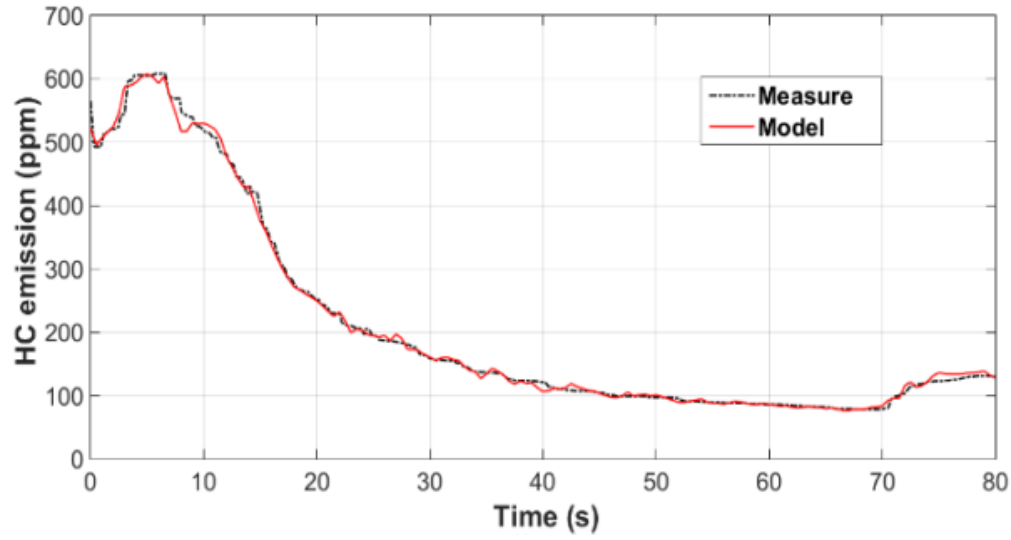

(a) 


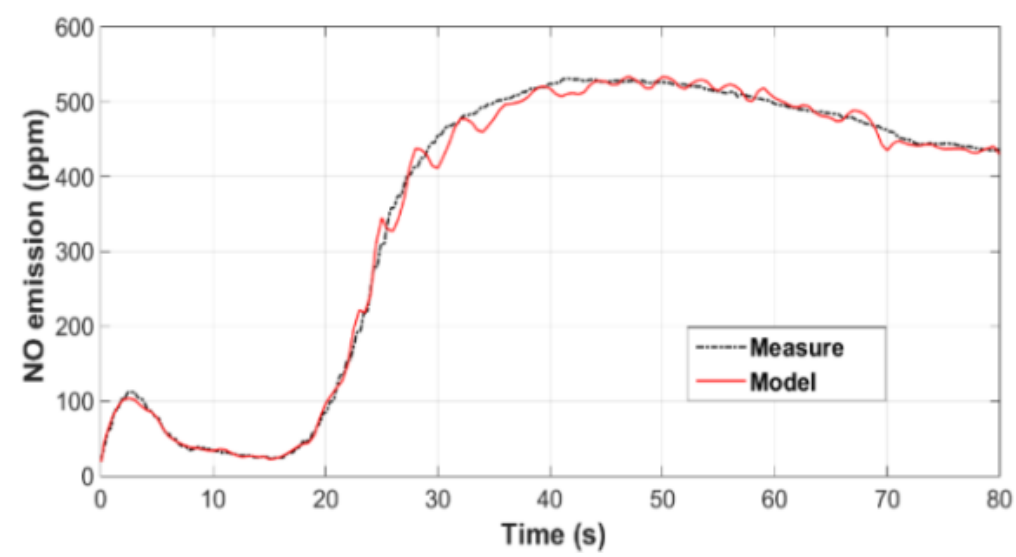

(b)

Figure 7. Engine-out (a) HC, (b) NO emissions. (red line: model, black dotted line: measurement).

Table 6. Mean absolute percentage error (MAPE) of model output compared to measurement results

\begin{tabular}{lc}
\hline Output & MAPE (\%) \\
\hline$\dot{M}_{\text {air }}$ & 0.537 \\
$\dot{M}_{\text {cyl }}$ & 0.560 \\
$P_{\text {im }}$ & 0.850 \\
$N$ & 0.545 \\
$T_{\text {catalyst }}$ & 0.419 \\
$H C$ emission & 2.645 \\
$N O$ emission & 3.020 \\
\hline
\end{tabular}

Figure 8, shows that increasing the overlap angle of the inlet and outlet cylinder valves - can reduce engine speed at engine speeds below $1000 \mathrm{rpm}$, but increases the engine speed when the speed is above $1000 \mathrm{rpm}$ (because at low engine speeds with increasing VO, the volumetric efficiency and engine speed are reduced due to extra increased residual gas $[18,19])$. This might be attributed to the variation of volumetric efficiency as a function of valve overlap angle at different engine speeds $[18,19]$.

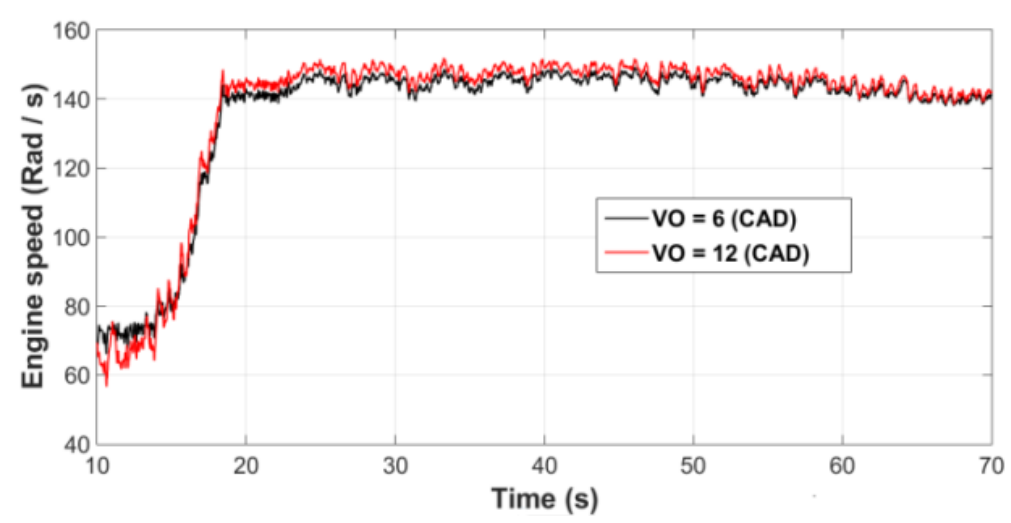

Figure 8. Influence of VO on engine speed. 


\section{Control Strategy in Cold Start Condition}

In conventional strategy [6,20], ECU applies a higher set-point for engine speed comparing to warm engine, to achieve fast warm-up of catalyst converter and engine speed stability. To achieve this target, ECU increases the opening area of the throttle valve and inject more fuel. Besides, in order to increase exhaust gas temperature, the controller retards ignition angle. Of course, retardation of ignition angle reduces the engine torque and speed, which is compensated by opening up the air path and more fuel injection. The common approach is to implement this strategy with a PID controller, which does not use the valve variable timing (VVT).

We propose the idea of increasing cylinder inlet and outlet valves overlapping angles (VO) during cold start. This results in the exhaust gas recirculation (EGR) rate. This method leads to reduction of $\mathrm{NO}_{\mathrm{x}}$ and $\mathrm{HC}$ emissions and accelerate warming up of inlet manifold, which in turn helps to homogenize the fuel mixture for better combustion [13, 21-24]. In addition, the increase in VO improves engine volumetric efficiency at higher engine speeds than normal idle engine speed and consequently increases engine efficiency and increase engine speed [19]. Therefore, by increasing the VO during the catalyst warm-up phase, the engine efficiency and engine speed can be increased more efficiently. Now, we may use this efficiency factor, to apply more retardation of the ignition angle and to accelerated catalyst warm-up phase [21], and reduce HC emission [13, 25].

\section{Fuzzy-Threshold Controller}

Following the former discussion, we apply a fuzzy-threshold controller based on the engine model developed for cold start condition. This controller is similar to a regular controller, except for $\mathrm{VO}$ and ignition angle, other input parameters are exactly in accordance with the regular controller. The threshold controller is used to control the VO. This controller is switched "ON" after in cold start condition and after passing the transient initial overshoot and undershoot and when the engine speed increases to above a certain threshold (1250 rpm). During "ON" condition, the controller increases the VO, which increases the engine speed, and reduces $\mathrm{NO}_{\mathrm{x}}$ and $\mathrm{HC}$ emissions [13]. Next, the fuzzy control strategy is applied to the ignition angle to increase combustion gas temperature. This controller also limits the valve overlap angle based on EGR rate input. EGR rate is estimated by ECU and is limited to 5\% to ensure a certain minimum thermodynamic efficiency for the engine. [17].

Figure 9 shows the algorithm governing the VO controller. The parameter OP1 in this figure represents the optimum $\mathrm{VO}$ for the engine speed in the warm-up phase that was obtained to be 10.5 CAD from experimental results. The parameter OP2 is also the optimum $\mathrm{VO}$ for engine speed in the idle condition of a warm engine that is $6 \mathrm{CAD}$. 


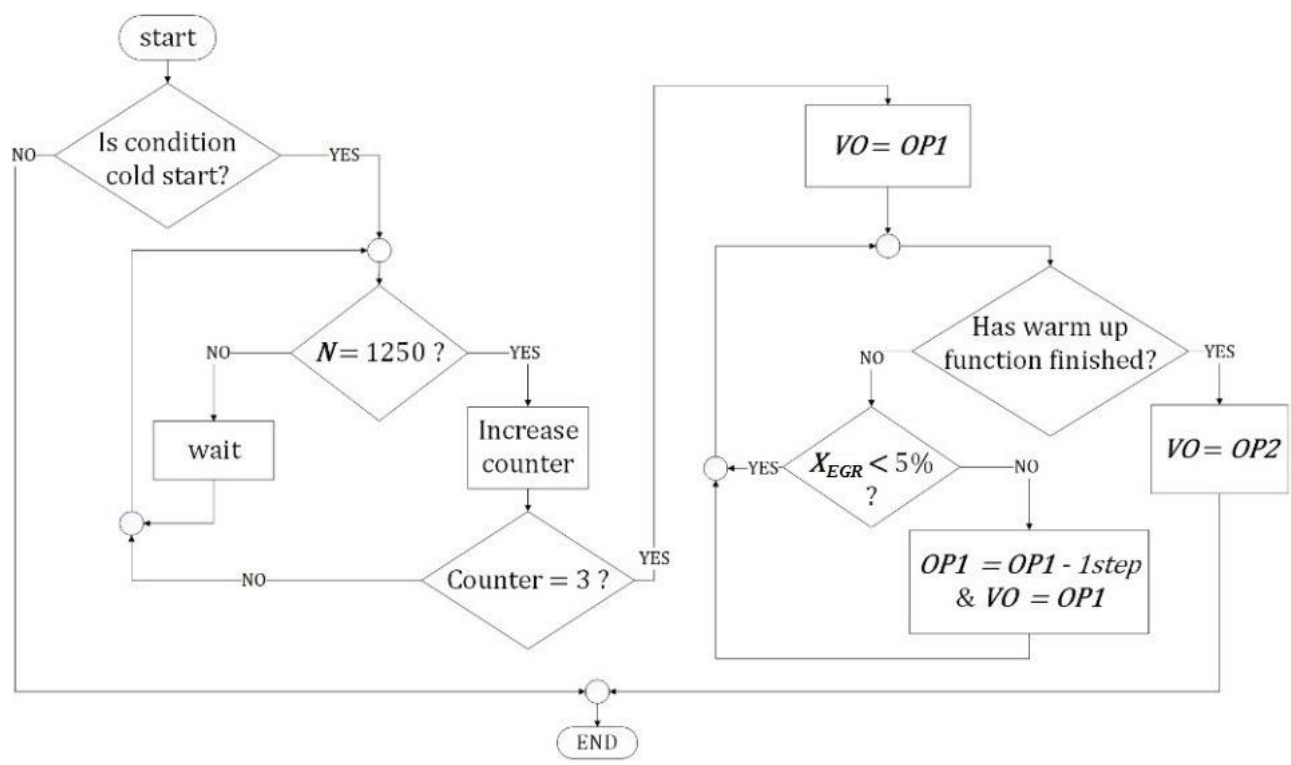

Figure 9. VO controller algorithm.

The input signal for the fuzzy controller is the difference between the reference engine speed and the current engine speed. The fuzzifier is triangular and trapezoidal. Fuzzy Inference engine for this controller is the minimum inference engine. This engine uses an inference that is based on individual rules, the Mamdani's minimum implication, and the min and max operators for all $t$ norms and $s$ norms, respectively. Therefore, this inference engine generates a fuzzy output set for each rule and by integrating these sets, the final output set will be achieved. Defuzzification is done by the centroid method, which is a commonly used method [26].

Table 7. Fuzzy rules for spark ignition angle.

\begin{tabular}{lc}
\hline Input membership function & Output membership function \\
\hline NM & BR \\
NS & MR \\
PS & SR \\
PM & MA \\
PB & BA \\
PVB & VBA \\
\hline
\end{tabular}

The fuzzy rules in this controller are based on the expert's experiences and have been written about the step response. These rules are designed so that whenever engine speed is lower than the reference speed, the speed reduction is prevented by advancing the ignition angle. In contrast, when the engine speed exceeds the reference speed, by retarding in the ignition angle, it attempts to converge engine speed to the reference and raise the exhaust gas temperature. The fuzzy rules are shown in Table 7. In the naming of the membership functions, $\mathrm{N}$ and $\mathrm{P}$ mean Negative and Positive respectively, and S, M, B and VB mean small, medium, large and very large respectively. A and $\mathrm{R}$ mean the retardation and advancing in ignition angle respectively. Figure 10 shows the membership function for the difference between engine speed and the reference speed (engine speed error) and the membership function of the ignition angle. 


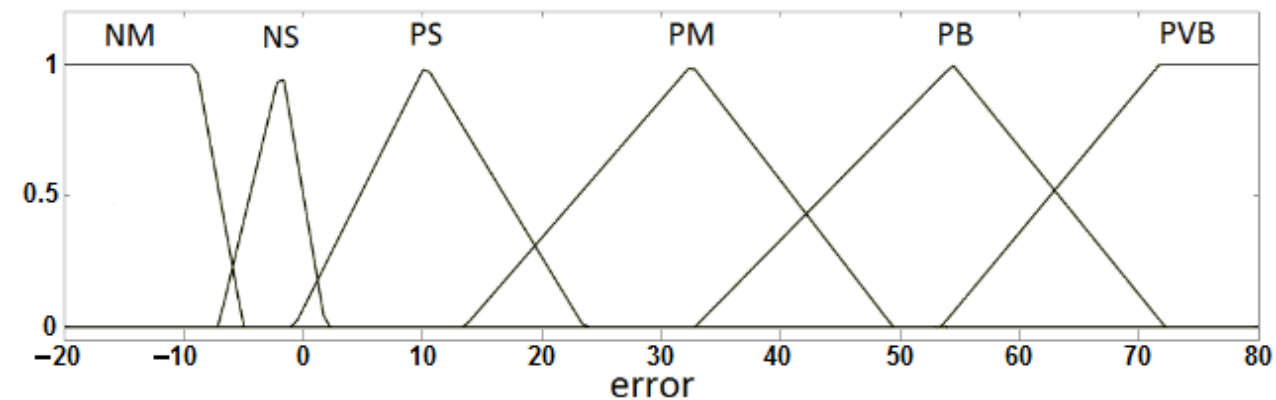

(a)

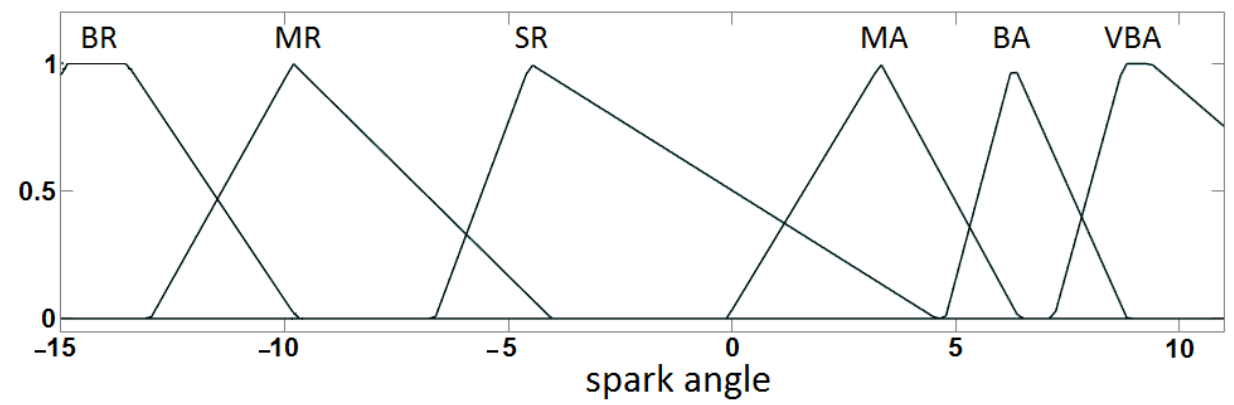

(b)

Figure 10. Membership function of engine speed error (a) and spark ignition angle (b).

Closed-loop simulation of the model and the controller are performed using MATLAB/Simulink software. To compare the performance of our controller with regular PID controller, both controllers were applied to the model and the results were compared. Simulation has also been performed under a critical engine operation condition to monitor the controller's performance in critical situations. For example, after starting the engine due to lack of proper control of the air/fuel ratio the engine speed drops fast and the engine shut down, that the proper control of the ignition angle can prevent engine shutdown. Figure 11, compare the engine speed sing both controllers, we observe that the fuzzy-threshold controller, shows almost similar characteristics to PID during the start, except for a small increase of the engine speed during transient undershoot, which is the positive feature and help to avoid engine stall. More importantly, the catalyst warm-up function is deactivated in our controller about $6 \mathrm{~s}$ earlier. Figure 12 shows exhaust gas temperature and catalyst temperature, based on two-controller, it confirms that the catalyst converter has reached its operating temperature about 6 seconds earlier using our proposed control strategy, which leads to a reduction of fuel consumption and harmful emissions.

Figure 13 shows the emission of $\mathrm{HC}$ and $\mathrm{NO}_{\mathrm{x}}$ during cold start condition, the cumulative concentration of $\mathrm{HC}$ and $\mathrm{NO}_{\mathrm{x}}$ emissions before the catalyst converter has been reduced about $3.5 \%$ and $8.5 \%$ using the fuzzy-threshold controller operation, respectively. Since the duration of the cold start has been reduced, the amount of fuel consumption in this period has also decreased by about $7 \%$. This result confirms that the proposed approach of using VO as a new degree of freedom is useful for reducing harmful emission during cold start. Another important feature of the proposed fuzzy threshold controller is that it can be integrated easily in ECU for the vehicles already equipped with VVT. 


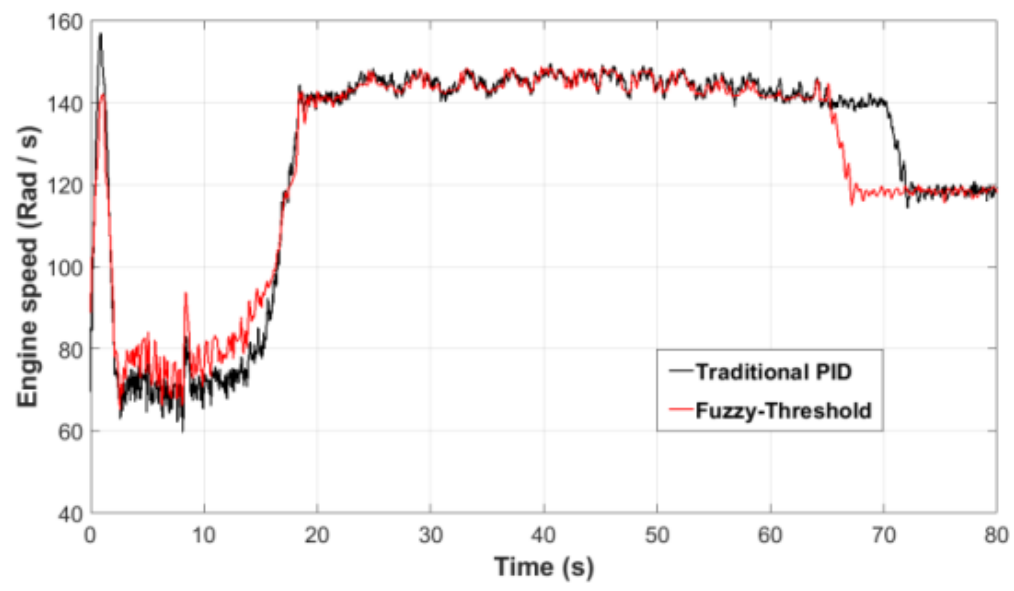

Figure 11. Engine speed obtained as a function of time during cold start. (red line: our controller, black dotted line: regular PID controller)

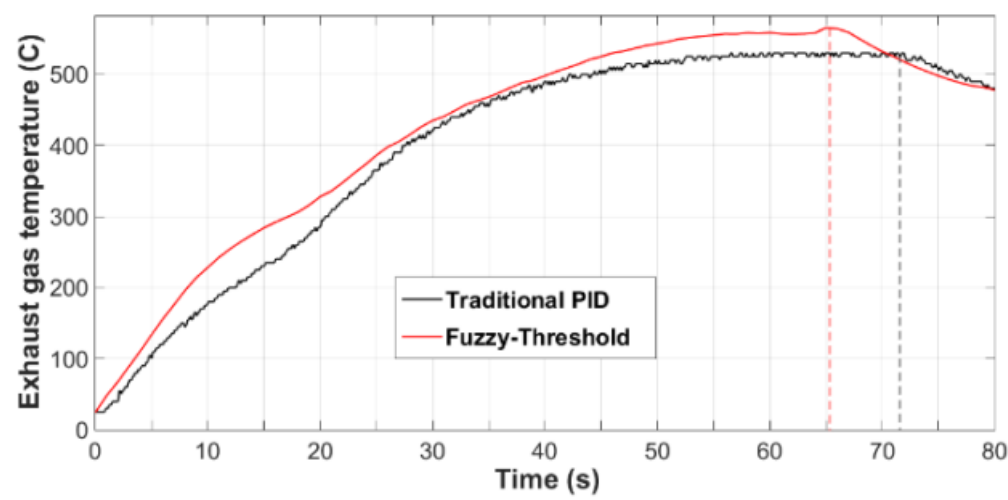

(a)

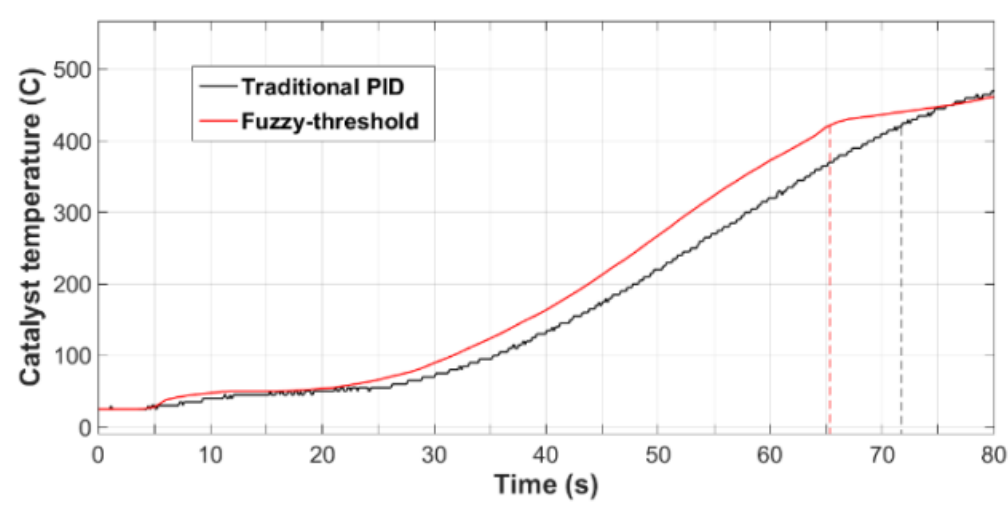

(b)

Figure 12. (a) Exhaust gas temperature during cold start and (b) catalyst temperature obtained by applying the fuzzy-threshold and traditional controller (red line: our controller, black dotted line: regular PID controller). 


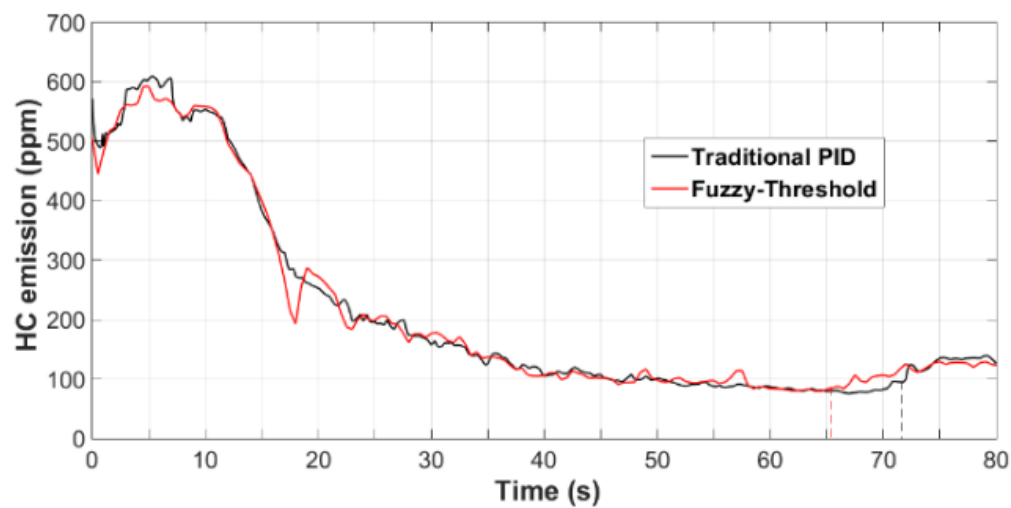

(a)

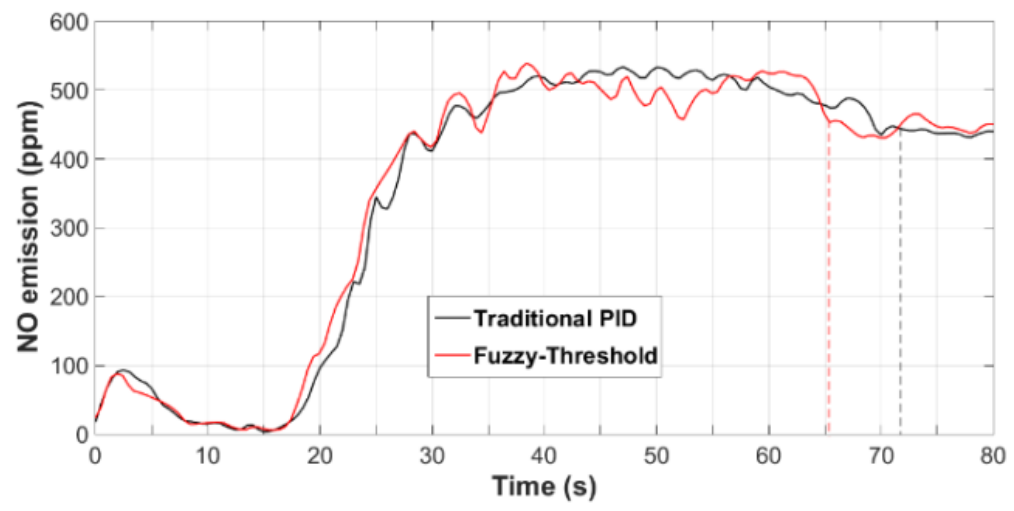

(b)

Figure 13. (a) HC emission as a function of time during cold start, (b) NO emission as a function of time during the cold start (red line: our controller, block dotted line: regular PID controller).

\section{CONCLUSION}

A controllable model of the internal combustion engine during cold start operating condition has been proposed and validated with experimental data. The model takes into account the effect of valve overlaps on engine efficiency and catalyst temperature. Using this model, we proposed a fuzzy-threshold controller using valve overlap as an extra degree of freedom in comparison to the regular PID controller. By increasing the VO during the catalyst warm-up phase, the engine efficiency and engine speed increases. This efficiency factor can be used to apply more retardation of the ignition angle and to accelerate catalyst warm-up phase, and to reduce $\mathrm{HC}$ and $\mathrm{NO}$ emissions. This control strategy reduces catalyst warm-up time about 6 seconds $(8.6 \%)$ and also reduces the cumulative concentration of $\mathrm{HC}$ and $\mathrm{NO}$ emissions about $3.5 \%$ and $8.5 \%$ respectively. Also, the amount of fuel consumed during the catalyst's warm-up phase has been reduced up to $7 \%$. This controller might be implemented with small modification on the software and calibration tables of the ECU for vehicles equipped with the VVT system.

\section{ACKNOWLEDGEMENT}

The authors would like to thank Crouse automotive part manufacturing for providing the experimental facilities. 


\section{REFERENCES}

[1] Iodice P, Senatore A. Analytical-experimental analysis of last generation mediumsize motorcycles emission behaviour under real urban conditions. International Journal of Automotive and Mechanical Engineering 2015; 12(1): 3018-3032.

[2] Bhaskar K, Nagarajan G, Sampath S. Experimental investigation of cold start emissions using electrically heated catalysts in a spark ignition engine. International Journal of Automotive and Mechanical Engineering 2010; 2(1): 105-118.

[3] Iodice P, Senatore A. A numerical-experimental approach to assess emission performance of new generation engines during the cold transient. International Journal of Automotive and Mechanical Engineering 2016; 13(3): 3599-3612.

[4] Stanglmaier RH, Li J, Matthews RD. The effect of in-cylinder wall wetting location on the HC Emissions from SI engines. SAE Technical paper: 1999-01-0502; 1999.

[5] Keynejad F, Manzie C. Cold start modelling of spark ignition engines. Control Engineering Practice 2011; 19(8): 912-925.

[6] Andrianov DI, Keynejad F, Dingli RJ, Voice G, Brear MJ, Manzie C. A cold start emissions model of an engine and after treatment system for optimization studies. SAE Technical Paper: 2010-01-1274; 2010.

[7] Manzie C, Keynejad F, Andrianov D, Dingli RJ, Voice G. a control-oriented model for cold start operation of spark ignition engines. In: IFAC Workshop on Engine and Powertrain Control, Simulation and Modelling, pp. 216-223; 2009.

[8] Edelberg K, Hedrick K. A high-level approach to mean value modeling of an automotive engine during cold-start. In: American Control Conference, pp. 31653170; 2014.

[9] Shahbakhti M, Li J, Hedrick JK. Early model-based verification of automotive control system implementation. In: American Control Conference pp. 3587-3592; 2012.

[10] Keynejad F, Manzie C. Suboptimal cold start strategies for spark ignition engines. IEEE transactions on control systems technology 2013; 21(4): 1295-1308.

[11] Andrianov DI, Manzie C, Brear MJ. Spark ignition engine control strategies for minimising cold start fuel consumption under cumulative tailpipe emissions constraints. Control Engineering Practice 2013; 21(8): 1007-1019.

[12] Khiar D, Lauber J, Floquet T, Colin G, Guerra TM, Chamaillard Y. Robust TakagiSugeno fuzzy control of a spark ignition engine. Control Engineering Practice 2007; 15(12): 1446-1456.

[13] Choi K, Lee H, Hwang I, Myung CL, Park S. Effects of various intake valve timings and spark timings on combustion, cyclic THC and NOx emissions during cold start phase with idle operation in CVVT engine. Journal of Mechanical Science and Technology 2008; 22(11): 2254-2262.

[14] Andwari AM, Aziz AA, Said MFM, Latiff ZA, Ghanaati A. Influence of hot burned gas utilization on the exhaust emission characteristics of a controlled auto-ignition two-stroke cycle engine. International Journal of Automotive and Mechanical Engineering 2015; 11: 2396-2404.

[15] Andrew R, Richard B, Philip S. Internal combustion engine cold-start efficiency: A review of the problem, causes and potential solutions. In Energy Conversion and Management 2014; 82: 327-350.

[16] Depcik C, Dennis A. One-dimensional automotive catalyst modeling. In Progress in Energy and Combustion Science 2005; 31(4): 308-369. 
[17] Guzzella L, Onder CH. Introduction to modeling and control of internal combustion engine systems. $2^{\text {nd }}$ ed. Springer Science and Business Media; 2010.

[18] Heywood JB. Internal combustion engine fundamental. New York: McGraw-Hill, Inc; 1988.

[19] Ghazimirsaied A, Jazayeri A, Shamekhi AH. Improving volumetric efficiency using intake valve lift and timing optimization in SI engine. International Review Of Mechanical Engineering 2010; 4(3): 244-252.

[20] Lang KR. Reducing cold start HC emission from port fuel injected spark ignition engine. PhD Thesis. Massachusetts Institute of Technology; 2006.

[21] Cho YS, Kim DS. Idle performance of an SI engine with variations in engine control parameter. International Journal of Automotive Technology 2006; 7(7): 763-768.

[22] Myung CL, Choi KH, Hwang IG, Lee KH, Park S. Effect of valve timing and intake flow motion control on combustion and time-resolved $\mathrm{HC} \& \mathrm{NOx}$ formation characteristic. International Journal of Automotive Technology 2009; 10(2): 161-166.

[23] Myung CL, Kwak H, Huang IG, Park S. Theoretical flow analysis and experimental study on time resolved THC formation with residual gas in a dual CVVT engine. International Journal of Automotive Technology 2007; 8(6): 697-704.

[24] Kim DS, Park YJ, Lee SW, Cho YS. A study on characteristics and control strategies of cold start operation for improvement of harmful exhaust emissions in SI engines. Journal of Mechanical Science Technology 2008; 22(1): 141-147.

[25] Rashid AK, Mansor MRA, Ghopa WAW, Harun Z, Mahmood WAFW. An experimental study of the performance and emissions of spark ignition gasoline engine. International Journal of Automotive and Mechanical Engineering 2016; 13(3): 3540-3554.

[26] Amindousta A, Ahmeda SH, Saghafiniab A, Bahreininejada A. Sustainable supplier selection: A ranking model based on fuzzy inference system. Applied Soft Computing Journal 2012; 12(6): 1668-1677. 